\title{
Association Between Screen Overuse and Behavioral and Emotional Problems in Elementary School Children
}

\author{
Yeonkyu Choi ${ }^{1}$, Dong Yun Lee ${ }^{2}$, Sangha Lee ${ }^{1}$, Eun-Jin Park ${ }^{3}$, Hee Jeong Yoo ${ }^{4}$, and Yunmi Shin ${ }^{1}$ \\ ${ }^{1}$ Department of Psychiatry, Ajou University School of Medicine, Suwon, Korea \\ ${ }^{2}$ Department of Biomedical Informatics, Ajou University School of Medicine, Suwon, Korea \\ ${ }^{3}$ Department of Psychiatry, Inje University Ilsan Paik Hospital, Goyang, Korea \\ ${ }^{4}$ Department of Psychiatry, Seoul National University Bundang Hospital, Seoul National University College of Medicine, Seongnam, Korea
}

\begin{abstract}
Objectives: This study identified the association between excessive exposure to screen media and behavioral and emotional problems in elementary school students.

Methods: A total of 331 parents of children aged 7-10 years were recruited from "The Kids Cohort for Understanding of Internet Addiction Risk Factors in Early Childhood (K-CURE)" study. Children's demographics, household media ownership, screen time, and behavioral/emotional problems were assessed using a parental questionnaire. Children's behavior/emotional problems were measured using the Korean version the of Child Behavior Checklist (K-CBCL) score.

Results: The total K-CBCL score in the screen overuse group was $51.18 \pm 9.55$, significantly higher than $47.28 \pm 10.09$ in the control group $(\mathrm{t}=2.14, \mathrm{p}=0.05)$. For each subscale, the externalization score $(51.65 \pm 10.14,48.33 \pm 8.97$, respectively; $\mathrm{t}=2.02, \mathrm{p}<0.05)$, social problem score $(55.41 \pm 6.11,53.24 \pm 5.19$, respectively; $\mathrm{t}=2.27, \mathrm{p}<0.05)$, and rule breaking behavior score $(55.71 \pm 6.11,53.24 \pm 5.19$, respectively; $\mathrm{t}=2.27, \mathrm{p}<0.05)$ were significantly higher in the screen overuse group than in the control group. In addition, the screen overuse group also had a significantly higher usage rate than the control group, even if limited to smartphones, not only on weekdays $(3.56 \pm 2.08,1.87 \pm 2.02$, respectively; $\mathrm{t}=-4.597, \mathrm{p}<0.001)$ but also weekends $(1.62 \pm 0.74,1.19 \pm 0.83$, respectively; $\mathrm{t}=-3.14, \mathrm{p}=0.003)$.

Conclusion: The study suggested that screen media overuse patterns in children in Korea are particularly relevant to the excessive use of smartphones and are related to higher risks of emotional and behavioral problems.
\end{abstract}

Keywords: Screen time; Smartphone; Child; Behavioral and emotional problems.

Received: May 13, 2021 / Revision: August 4, 2021 / Accepted: August 18, 2021

Address for correspondence: Yunmi Shin, Department of Psychiatry, Ajou University School of Medicine, 164 World cup-ro, Yeongtong-gu, Suwon 16499, Korea

Tel: +82-31-219-5180, Fax: +82-31-219-5179, E-mail: ymshin@ajou.ac.kr

\section{INTRODUCTION}

Screen media devices are indispensable in our lives. Thanks to the spread of these devices, the "digital native" generation is quite familiar with media culture [1]. The prevalence of smart devices has enabled access to media anytime; use is not limited to a particular location or device, such as a television or computer. According to data released by the Organization for Economic Cooperation and Development (OECD), $95 \%$ of children in OECD countries had Internet access in their homes in 2015, an increase of more than $20 \%$ from a decade ago [2].

With this trend, children have gradually begun to spend more time in front of screens. According to a study, students spent twice as much time online in 2016 as they did 10 years

This is an Open Access article distributed under the terms of the Creative Commons Attribution Non-Commercial License (https://creativecommons.org/licenses/by-nc/4.0) which permits unrestricted non-commercial use, distribution, and reproduction in any medium, provided the original work is properly cited. before. In 2008, only half of the students visited social media sites daily, whereas this percentage had grown to $82 \%$ in $2016[3]$.

Concerns have continuously been raised that exposure to screen media devices at a young age has a negative impact on children. In particular, it has been suggested that screen time causes not only physical problems (e.g., interference with children's sleep and eating habits, as well as obesity), but also in a wide range of areas, including behavior, hyperactivity, emotions, and relationships with peers [4-9]. As these negative results are announced one after another, guidelines for the use of smart devices by children are being established in various countries. Since 1999, the American Academy of Pediatrics has consistently generated guidelines for children's media use, and the World Health Organization (WHO) released a revised guideline on the same topic in 2019 [10,11]. However, although most guidelines strictly regulate very young children's exposure to screen media, they remain rel- 
atively vague about the use of media devices in school-age children.

In Korea, where the information technology industry is the most advanced in the world, children's media exposure is also the highest in the world [12]. In particular, Korea's smartphone penetration rate is the highest in the world, and most children are exposed to media culture via such devices. In $2018,81.2 \%$ of lower-grade elementary school students in Korea had their own smartphones, a steep increase of more than $20 \%$ compared to 2015 [13]. This percentage is much higher than the $51 \%$ surveyed on the same subject in the United States in the same year [14]. Given this growing trend, it can be expected that smartphones will be central to screen media in the future; hence, it is necessary to learn more about how children are using them.

The current study is a sub-study of a long-term observational prospective cohort study aimed at understanding the use of screen media devices among children in Korea. This investigated the effects of screen media overuse on emotional and behavioral problems in children.

\section{METHODS}

\section{Study sample}

We invited 331 parents of children aged 7-10 years to participate in "The Kids Cohort for Understanding of Internet Addiction Risk Factors in Early Childhood (K-CURE)" study. The K-CURE study is the first long-term active cohort study in Korea for analyzing the causes and effects of media-related disorders and diseases in children. Caregivers voluntarily visited community centers for children's mental health in Goyang, Seongnam and Suwon, the major cities in Gyeonggi Province, where the largest populations in Korea live. The baseline assessment (Wave 1) was conducted between December 2015 and July 2016, and follow-up assessments (Waves 2 to 5) were conducted annually over the subsequent four years. In the first wave, 400 caregivers of children aged 2-5 years were enrolled. Inclusion criteria were children aged 2-5 years at baseline and consent to participate in the study. Exclusion criteria were if the child had a serious physical illness or developmental problem or the guardian's lack of Korean language ability. This study was conducted using data from Wave 5 of the K-CURE study.

\section{Measures}

\section{Demographics}

Respondents were asked to report on the following: their child's sex, age, main caregiver, maternal and paternal employment status, and family income. Family income was as- sessed using the question, "What is your average monthly family income?" Response options were "less than 1000000 Korean won (1M KRW)," "1M-2M KRW," “2M-4M KRW," “4M-6M KRW," and "over 6M KRW."

\section{Household media ownership}

Respondents were asked if they had the following types of devices: televisions (TVs), computers (e.g., desktops and laptops), tablet PCs, and smartphones.

\section{Screen time}

Screen time was defined as the total time that children used screen media devices. The screen media devices surveyed included TVs, PCs, tablet PCs, smartphones, video game consoles, and portable game consoles. Respondents were also asked about their children's screen time, including the frequency and duration of use of a digital screen device. In response to the frequency of use, participants were asked to indicate the number of days each device was used for a week. Response options for the average amount of media use per day were "none" (=0), "less than one hour" $(=1)$, "1-2 hours" (=2), "2-3 hours" (=3), " $3-4$ hours" (=4), and " 4 hours or more" (=5).

\section{Behavioral problems}

The Korean version of the Child Behavior Checklist (KCBCL) is a 113-item parent-report measure used to assess a broad range of emotional and behavioral syndromes among children aged 4 to 17 years [15]. The K-CBCL includes eight syndrome scales: anxious/depressed (e.g., "fears doing bad [things]"), withdrawn/depressed (e.g., "[would] rather be alone"), somatic complaints (e.g., "nightmares"), social problems (e.g., "unliked"), thought problems (e.g., "hears things"), attention problems (e.g., "acts too young"), rule-breaking behavior (e.g., "lack of guilt"), and aggressive behavior (e.g., "attacks people"). Respondents answered questions on a threepoint scale: not true, somewhat/sometimes true, or very true/ often true. A T-score, with a mean of 50 points and standard deviation of 10 points based on normative data, is produced by the K-CBCL for internalizing (e.g., anxious/depressed, withdrawal, somatic, emotionally reactive), externalizing (e.g., inattention, aggressiveness), and total problems (internalizing, externalizing, sleep issues, and other problems) [16]. The reliability and validity of the K-CBCL are well-established for Korean children and adolescents. The Cronbach's alpha values for the K-CBCL ranges from 0.62 to 0.95 [17].

\section{Statistical analysis}

Data were analyzed using the Statistical Package for the Social Sciences (SPSS) version 25.0 (IBM Corp., Armonk, NY, USA). We conducted a frequency analysis and obtained de- 
scriptive statistics for the demographic information. This study follows a normal distribution. For data composed of continuous variables, a t-test was used, and a chi-square test was used for the response rate.

\section{Ethics statement}

The study was approved by the Institutional Review Board (IRB) of the Ajou University School of Medicine (AJIRBSBR-SUR-14-378). All participants provided prior consent during the registration.

\section{RESULTS}

\section{Participants' demographic characteristics}

Children who used screen media devices for more than five days during the week and whose daily screen time was at least two hours were categorized as the screen overuse group. A control group was maintained for comparison. The criteria were determined by referring to the standards set by the $\mathrm{Ca}$ nadian 24-hour Movement Guidelines, Australia's Physical Activity and Sedentary Behavior Guidelines for Families, and the Korea Communications Commission's survey on the use of broadcasting media [18-20]. The demographic characteristics of the sample are outlined in Table 1 . The number of children in the screen overuse group was 34 (10.3\%) and 297 (89.7\%) in the control group. The proportion of children for each age group differed slightly between groups. In particular, the proportion of 10 -year-old children in the screen overuse group was $31.7 \%$, which was higher than the $9.4 \%$ in the control group. However, this difference was not statistically significant. The family income level was significantly different between groups $\left(\chi^{2}=12.795, p=0.012\right)$, with the highest in-

Table 1. Demographic characteristics of participants

\begin{tabular}{|c|c|c|c|c|c|}
\hline Characteristics & $\begin{array}{c}\text { Total } \\
(n=331)\end{array}$ & $\begin{array}{c}\text { Screen overuse } \\
(\mathrm{n}=34,10.3 \%)\end{array}$ & $\begin{array}{c}\text { Control } \\
(n=297,89.7 \%)\end{array}$ & $\chi^{2}$ & $p$ \\
\hline Age & & & & 6.347 & 0.096 \\
\hline 7 years & $52(15.7)$ & $7(20.6)$ & $45(15.2)$ & & \\
\hline 8 years & $139(42.0)$ & $9(26.5)$ & $130(43.8)$ & & \\
\hline 9 years & $105(31.7)$ & $11(32.4)$ & $94(31.6)$ & & \\
\hline 10 years & $35(10.6)$ & $7(31.7)$ & $28(9.4)$ & & \\
\hline Sex & & & & 0.353 & 0.552 \\
\hline Male & $169(51.1)$ & $19(55.9)$ & $150(50.5)$ & & \\
\hline Female & $162(48.9)$ & $15(44.1)$ & $147(49.5)$ & & \\
\hline Family income, KRW & & & & 12.795 & $0.012^{*}$ \\
\hline$<1 M$ & $1(0.3)$ & $0(0.0)$ & $1(0.3)$ & & \\
\hline $1-2 \mathrm{M}$ & $10(3.0)$ & $3(8.8)$ & $7(2.4)$ & & \\
\hline $2-4 \mathrm{M}$ & $92(27.8)$ & $16(47.1)$ & $76(25.6)$ & & \\
\hline $4-6 M$ & $127(38.4)$ & $8(23.5)$ & $119(40.1)$ & & \\
\hline$>6 \mathrm{M}$ & $101(30.5)$ & $7(20.6)$ & $94(31.6)$ & & \\
\hline \multicolumn{6}{|l|}{ Possession ratio } \\
\hline TV & 316 (95.5) & $33(97.1)$ & $283(95.3)$ & 0.222 & 0.683 \\
\hline Computer & $284(85.8)$ & $24(70.6)$ & $260(87.5)$ & 7.198 & $0.007^{* *}$ \\
\hline Tablet PC & $228(68.9)$ & $17(50.0)$ & $211(71.0)$ & 6.303 & $0.012^{*}$ \\
\hline Smartphone & $308(93.1)$ & $31(91.2)$ & 277 (93.3) & 0.206 & 0.650 \\
\hline \multicolumn{6}{|l|}{ Parent employment status } \\
\hline Father & & & & 0.464 & 0.496 \\
\hline Employed & $327(98.8)$ & $34(100.0)$ & $293(98.7)$ & & \\
\hline Unemployed & $4(1.2)$ & $0(0.0)$ & $4(1.3)$ & & \\
\hline Mother & & & & 0.138 & 0.710 \\
\hline Employed & $156(47.1)$ & $15(44.1)$ & $141(47.5)$ & & \\
\hline Unemployed & $175(52.9)$ & $19(55.9)$ & $156(52.5)$ & & \\
\hline Main caregiver & & & & 0.043 & 0.835 \\
\hline Mother & $314(94.9)$ & $32(94.1)$ & $282(94.9)$ & & \\
\hline Others & $17(5.1)$ & $2(5.9)$ & $15(5.1)$ & & \\
\hline BMI $\left(\mathrm{kg} / \mathrm{m}^{2}\right)$, mean (SD) & $16.6(2.46)$ & $17.4(3.10)$ & $16.5(2.36)$ & 1.980 & $0.049^{*}$ \\
\hline
\end{tabular}

Data are presented as $n(\%)$ unless otherwise indicated. ${ }^{*} \mathrm{p}<0.05 ;{ }^{* *} \mathrm{p}<0.01$. BMI, body mass index; SD, standard deviation 
come level for the screen overuse group in the range of $2-4 \mathrm{M}$ KRW per month (47.1\%). For the control group, the highest income level was 4-6M KRW. Most of the fathers (98.7\%) and nearly half of the mothers were employed (47.5\%). The average body mass index (BMI) of the children in the screen overuse group was $17.4 \pm 3.1$, compared to $16.5 \pm 2.4$ in the control group. Thus, BMI was significantly higher in the screen overuse group $\left(\chi^{2}=1.98, \mathrm{p}=0.049\right)$. It should be noted that among the screen media devices investigated, there was a difference in retention between the screen overuse and control groups depending on the type of device. In the screen overuse group, $70.6 \%$ had computers at home, compared to $87.5 \%$ in the control group $\left(\chi^{2}=7.198, \mathrm{p}=0.007\right)$. For tablet PCs, the difference was $50.0 \%$ and $71.0 \%$, respectively. The possession rates for TVs and smartphones were not significantly different between the two groups $\left(\chi^{2}=6.303, p=0.012\right)$. Furthermore, there was no significant difference between the two groups in terms of parents' employment status and the mother's role (i.e., whether she was the main caregiver).

\section{Smartphone usage patterns}

The smartphone usage patterns of the screen overuse and control groups are reported in Table 2. The frequency of use on weekdays was $3.56( \pm 2.08)$ days for the overuse group, which was almost twice as high as the $1.87( \pm 2.02)$ days of usage in the control group $(\mathrm{p}<0.001)$. There was a significant difference in the frequency of use on the weekends: $1.62( \pm 0.74)$ days for the screen overuse group and $1.19( \pm 0.83)$ days for the control group $(\mathrm{t}=-3.14, \mathrm{p}=0.003)$. Since smartphone usage time was a categorical variable, the difference in ratios was compared with a chi-square test, which also showed a remarkable difference between the two groups. The percentage of children who used smartphones for more than two hours per day on weekdays was $55.6 \%$ for the screen overuse group compared to $0.6 \%\left(\chi^{2}=95.912, \mathrm{p}<0.001\right)$ for the control group. Regarding weekend smartphone use time, $69.0 \%$ of the screen overuse group used these devices for more than two hours per day, whereas this was only $14.7 \%\left(\chi^{2}=4.231, \mathrm{p}<0.001\right)$ in the control group. However, there was no difference between the two groups in terms of the age when smartphone use began, nor was there a difference in the ratio of smartphone cousers. Interestingly, the percentage of children who used smartphones outside the home was $10.3 \%$ in the screen overuse group and $28.1 \%$ in the control group (a significant difference: $\chi^{2}=4.208, \mathrm{p}=0.040$ ).

\section{Behavioral problems}

The results of K-CBCL tests for each group are reported in Table 3. The total T-score and T-scores of the subscales are also presented. The total K-CBCL score for the overuse group was $51.18 \pm 9.55$ points, significantly higher than the $47.28 \pm$ 10.09 points for the control group $(\mathrm{t}=2.14, \mathrm{p}<0.05)$ (Table 2). For each subscale, the externalization score of the screen overuse group was significantly higher than that of the control group (51.65 $\pm 10.14,48.33 \pm 8.97$, respectively; $\mathrm{t}=2.02, \mathrm{p}<$ $0.05)$. Regarding social problems, the score for the screen

Table 2. Comparison of smartphone usage between screen overuse group and control group

\begin{tabular}{|c|c|c|c|c|c|}
\hline & Total & Screen overuse & Control & $\chi^{2} / \dagger$ & $\mathrm{p}$ \\
\hline Weekdays frequency, day (SD) & $2.05(2.09)$ & $3.56(2.08)$ & $1.87(2.02)$ & -4.597 & $<0.001$ \\
\hline Weekend frequency, day (SD) & $1.24(0.83)$ & $1.62(0.74)$ & $1.19(0.83)$ & -3.14 & $0.003^{* *}$ \\
\hline Weekdays usage time per a day & & & & 95.912 & $<0.001$ \\
\hline Less than 2 hrs & $184(92.0)$ & $12(44.4)$ & $172(99.4)$ & & \\
\hline 2 hrs or more & $16(8.0)$ & $15(55.6)$ & $1(0.6)$ & & \\
\hline weekend usage time per a day & & & & 4.231 & $<0.001$ \\
\hline Less than $2 \mathrm{hrs}$ & $194(78.9)$ & $9(31.0)$ & $185(85.3)$ & & \\
\hline 2 hrs or more & $52(21.1)$ & $20(69.0)$ & $32(14.7)$ & & \\
\hline Starting age of smartphone & & & & 0.803 & 0.370 \\
\hline$<24$ months & $77(23.3)$ & $10(29.4)$ & $67(22.6)$ & & \\
\hline$>24$ months or none & $254(76.7)$ & $24(70.6)$ & $230(77.4)$ & & \\
\hline Smartphone co-user & & & & 2.893 & 0.235 \\
\hline Alone & $80(30.3)$ & $11(37.9)$ & $69(29.4)$ & & \\
\hline Main caregiver & $102(38.6)$ & $7(24.2)$ & $95(40.4)$ & & \\
\hline Others & $82(31.1)$ & $11(37.9)$ & $71(30.2)$ & & \\
\hline Location of smartphone use & & & & 4.208 & $0.040^{*}$ \\
\hline Home & $195(73.9)$ & $26(89.7)$ & $169(71.9)$ & & \\
\hline Other & $69(26.1)$ & $3(10.3)$ & $66(28.1)$ & & \\
\hline
\end{tabular}

Data are presented as $n(\%)$ unless otherwise indicated. ${ }^{*} \mathrm{p}<0.05 ;{ }^{* *} \mathrm{p}<0.01$. SD, standard deviation 
Table 3. Comparison of K-CBCL mean score between screen overuse group and control group $(n=331)$

\begin{tabular}{|c|c|c|c|c|}
\hline & Screen overuse $(n=34)$ & Control $(n=297)$ & $t$ & $\mathrm{p}$ \\
\hline K-CBCL total & $51.18 \pm 9.55$ & $47.28 \pm 10.09$ & 2.14 & 0.033* \\
\hline Internalizing & $51.38 \pm 8.81$ & $48.99 \pm 8.77$ & 1.51 & 0.133 \\
\hline Externalizing & $51.65 \pm 10.14$ & $48.33 \pm 8.97$ & 2.02 & $0.044^{*}$ \\
\hline Anxious/depressed & $54.35 \pm 6.34$ & $53.61 \pm 5.51$ & 0.73 & 0.463 \\
\hline Withdrawn & $54.35 \pm 5.61$ & $52.79 \pm 4.69$ & 1.80 & 0.073 \\
\hline Somatic complaints & $53.15 \pm 5.25$ & $53.15 \pm 5.12$ & 0.00 & 0.999 \\
\hline Social problems & $55.41 \pm 6.11$ & $53.24 \pm 5.19$ & 2.27 & $0.024^{*}$ \\
\hline Thought problems & $52.97 \pm 4.87$ & $53.53 \pm 5.53$ & 0.56 & 0.575 \\
\hline Attention problems & $52.85 \pm 4.52$ & $51.95 \pm 3.85$ & 1.12 & 0.268 \\
\hline Rule breaking behavior & $55.71 \pm 6.08$ & $53.06 \pm 4.52$ & 2.46 & $0.018^{*}$ \\
\hline Aggressive behavior & $54.29 \pm 6.69$ & $52.83 \pm 4.96$ & 1.57 & 0.118 \\
\hline Other problems & $55.29 \pm 5.92$ & $53.39 \pm 5.60$ & 1.86 & 0.063 \\
\hline
\end{tabular}

Data are presented as mean \pm standard deviation. ${ }^{*} \mathrm{p}<0.05 . \mathrm{K}-\mathrm{CBCL}$, Korean version the of Child Behavior Checklist

overuse group was significantly higher $(55.41 \pm 6.11,53.24 \pm$ 5.19 , respectively; $\mathrm{t}=2.27, \mathrm{p}<0.05)$. In addition, the rule-breaking behavior score was significantly higher in the overuse group than in the control group $(55.71 \pm 6.08,53.06 \pm 4.52$, respectively; $\mathrm{t}=2.46, \mathrm{p}=0.018$ ).

\section{DISCUSSION}

This study identified the usage patterns of Korean children who regularly use screen media devices and determine the associated emotional and behavioral problems.

One of the significant differences between the screen overuse group and the control group was family income. This is in line with previous studies that show a link between low household income levels and high levels of screen time among children [21,22]. Considering that another significant difference between the two groups is the BMI, it should be possible to determine how considerable screen time relates to other sedentary behaviors and physical activities.

The results highlight the need to focus on smartphones and their effects on infants and children in Korea. In fact, the penetration rate of smartphones in Korea is $95 \%$, which is significantly higher than that for the U.S. (81\%) and Japan (66\%) [12]. Of course, TV accounts for the largest portion of screen time for infants and children, but its usage and importance are gradually decreasing throughout the world [23]. According to a study published in 2019, Korean teenagers' smartphone usage was three times that of TVs. Smartphones are recognized as necessary media for daily life (more so than PCs and TVs) [19]. The findings of the current study reflect this trend and demonstrate the need to focus on smartphones, especially among screen media that affect children.

It is important to note that the screen overuse group had a significantly higher percentage of smartphones, primarily at home, than the control group. Unlike digital media devices, such as TVs and PCs, a smartphone can be used anywhere, but children in the screen overuse group tended to use the device the most while at home. This suggests that the overuse of digital media devices may be particularly relevant to patterns of use at home. Therefore, to prevent overuse, it may be necessary to pay attention to the use of devices at home and prepare specific countermeasures.

The screen overuse group had significantly higher K-CBCL scores than the control group, especially for social problems and rule-breaking behavior. Items associated with a social problems include not getting along, being teased and not liked, feeling persecuted, and being the target of fights and attacks. Those with social problems are usually seen as immature and clumsy and have poor peer relationships. This finding is in line with previous studies indicating negative associations between screen time and peer relationship problems [24]. As social activities (via social network services, instant messaging) through Internet media are increasing daily, the impact of these activities on children's social skills may be quite complex [25]. Therefore, future research should consider not only the amount of screen media, but also the specific types of media and the detailed activities through them.

The rule-breaking behavior scale included the following items: "does not seem to feel guilty after misbehaving," "lies or cheats," "is disobedient at home, school, or other places," and "steals outside the home." There is the possibility of a link between rule-breaking behavior and an underlying tendency for sensation-seeking [26]. It is well known that children who tend to be sensation-seeking are vulnerable to screen media addiction [27]. Sensation-seeking can also be the key to solving these problems because children with this tendency tend to engage in rule-breaking behavior [28]. It may be necessary to explain that only the rule-breaking behavior sub- 
scale has increased, except for aggressive behavior. Previous longitudinal research has shown that the two behaviors follow different developmental pathways [29].

These results indicate that children in the screen overuse group were more likely to be classified as having clinically significant externalization behavior problems, consistent with the results of previous studies in other countries showing the link between screen time and behavior problems in children [7,30,31].

This study is meaningful in its analysis of Korean children's smartphone usage patterns through the cohort data and the identification of these patterns with children's behavioral problems.

This study has the following limitations. Since this was a cross-sectional study, we should be wary of multiple biases that may emerge in the process of revealing interrelationships. Therefore, it is too early to determine whether the social problems, rule-breaking behavior, and screen overuse presented herein are interrelated risk factors or results. Follow-up studies are needed to better understand these associations. However, we did not implement other procedures for K-CBCL scores because they were already standardized.

The internalizing problem was not highlighted significantly compared to the externalizing problem. One corresponding hypothesis is that parents are sensitive to children's externalizing problems, whereas it is relatively difficult to accurately report their internalizing problems. It is possible that parents' reports have reduced children's sensitivity to subjective emotions. Indeed, it is widely accepted that children's reports are becoming increasingly important because many of the problems experienced by children remain unnoticed by their parents [32]. Subsequent studies will require children's self-written reports, in addition to parents' reports.

It is meaningful that we have confirmed that screen time is a significant variable leading to problem behavior in domestic cohorts. Thus, we should focus on revealing the association between screen time and these problems in more diverse ways and perspectives, starting with these findings.

\section{CONCLUSION}

The findings of this study suggest that screen media overuse patterns in children aged 7 to 10 years in Korea are particularly relevant to the excessive use of smartphones and may point to higher risks for emotional/social/behavioral issues. To address these issues, further research and guidance will be needed to present the use of screen media devices from a wider scope.

\section{Availability of Data and Material}

The datasets generated or analyzed during the study are available from the corresponding author on reasonable request.

\section{Conflicts of Interest}

Hee Jeong Yoo, a contributing editor of the Journal of the Korean Academy of Child and Adolescent Psychiatry, was not involved in the editorial evaluation or decision to publish this article. All remaining authors have declared no conflicts of interest.

\section{Author Contributions}

Conceptualization: Yeonkyu Choi, Yunmi Shin. Data curation: Eun-Jin Park, Hee Jeong Yoo. Formal analysis: Sangha Lee. Funding acquisition: Yunmi Shin. Investigation: Yunmi Shin, Eun-Jin Park, Hee Jeong Yoo. Methodology: Sangha Lee, Dong Yun Lee. Supervision: Yunmi Shin. Validation: Dong Yun Lee. Writing_original draft: Yeonkyu Choi. Writing_review \& editing: Yunmi Shin, Dong Yun Lee.

\section{ORCID iDs}

$\begin{array}{ll}\text { Yeonkyu Choi } & \text { https://orcid.org/0000-0002-3405-8089 } \\ \text { Dong Yun Lee } & \text { https://orcid.org/0000-0002-3678-9862 } \\ \text { Sangha Lee } & \text { https://orcid.org/0000-0002-7042-2052 } \\ \text { Eun-Jin Park } & \text { https://orcid.org/0000-0003-4046-1517 } \\ \text { Hee Jeong Yoo } & \text { https://orcid.org/0000-0003-0521-2718 } \\ \text { Yunmi Shin } & \text { https://orcid.org/0000-0001-9880-4004 }\end{array}$

\section{Funding Statement}

This research was supported by the grant from the Korean Mental Health Technology R\&D Project, Ministry of Health \& Welfare, Republic of Korea (HL19C0012).

\section{REFERENCES}

1) Stiglic N, Viner RM. Effects of screentime on the health and wellbeing of children and adolescents: a systematic review of reviews. BMJ Open 2019;9:e23191.

2) Gottschalk F. Impacts of technology use on children: exploring literature on the brain, cognition and well-being. OECD Education Working Papers No. 195 [Internet]. Paris: OECD Publishing;2019 [cited 2021 March 15]. Available from: https://doi. org $/ 10.1787 / 8296464 \mathrm{e}$-en.

3) Twenge JM, Martin GN, Spitzberg BH. Trends in US adolescents' media use, 1976-2016: the rise of digital media, the decline of TV, and the (near) demise of print. Psychol Pop Media Cult 2019;8:329345.

4) Genuneit J, Brockmann PE, Schlarb AA, Rothenbacher D. Media consumption and sleep quality in early childhood: results from the Ulm SPATZ health study. Sleep Med 2018;45:7-10.

5) Vijakkhana N, Wilaisakditipakorn T, Ruedeekhajorn K, Pruksananonda $\mathrm{C}$, Chonchaiya W. Evening media exposure reduces night-time sleep. Acta Paediatr 2015;104:306-312.

6) Miguel-Berges ML, Santaliestra-Pasias AM, Mouratidou T, Androutsos O, de Craemer M, Pinket AS, et al. Associations between food and beverage consumption and different types of sedentary behaviours in European preschoolers: the ToyBox-study. Eur J Nutr 2017;56:1939-1951.

7) Wu X, Tao S, Rutayisire E, Chen Y, Huang K, Tao F. The relationship between screen time, nighttime sleep duration, and behavioural problems in preschool children in China. Eur Child Adolesc Psychiatry 2017;26:541-548.

8) Ribner A, Fitzpatrick C, Blair C. Family socioeconomic status moderates associations between television viewing and school readi- 
ness skills. J Dev Behav Pediatr 2017;38:233-239.

9) Carson V, Rahman AA, Wiebe SA. Associations of subjectively and objectively measured sedentary behavior and physical activity with cognitive development in the early years. Ment Health Phys Act 2017; 13:1-8.

10) Council on Communications and Media. Media use by children younger than 2 years. Pediatrics 2011;128:1040-1045.

11) World Health Organization. Guidelines on physical activity, sedentary behaviour and sleep for children under 5 years of age [Internet]. Geneva: World Health Organization;2019 [cited 2021 March 15]. Available from: https://www.who.int/publications/i/ item/9789241550536/.

12) Taylor K, Silver L. Smartphone ownership is growing rapidly around the world, but not always equally [Internet]. Washington: Pew Research Center;2019 [cited 2021 March 15]. Available from: https:// www.pewresearch.org/global/2019/02/05/smartphone-ownershipis-growing-rapidly-around-the-world-but-not-always-equally/.

13) Ministry of Science and ICT. The survey on smartphone overdependence 2018 [Internet]. Gwacheon: Ministry of Science and ICT;2018 [cited 2021 March 15]. Available from: https://www.nia. or.kr/site/nia_kor/ex/bbs/View.do?cbIdx $=65914 \& b c I d x=20876 \& p$ arentSeq $=20876$.

14) Auxier B, Anderson M, Perrin A, Turner E. Parenting children in the age of screens [Internet]. Washington: Pew Research Center;2020 [cited 2021 March 15]. Available from: https://www.pewresearch. org/internet/2020/07/28/parenting-children-in-the-age-of-screens/.

15) Oh K, Lee H, Hong K, Ha E. Korean version of Child Behavior Checklist (K-CBCL). Seoul: Chung Ang Aptitude Publishing Co;1997.

16) Achenbach TM, Ruffle TM. The Child Behavior Checklist and related forms for assessing behavioral/emotional problems and competencies. Pediatr Rev 2000;21:265-271.

17) Kim M, Lee J, Kim Y, Ha E, Oh K. Secular changes in behavior problems of Korean youths based on the Korean-CBCL and-YSR. Kor J Psychol 2015;34:769-793.

18) Tremblay MS, Carson V, Chaput JP, Connor Gorber S, Dinh T, Duggan M, et al. Canadian 24-hour Movement Guidelines for children and youth: an integration of physical activity, sedentary behaviour, and sleep. Appl Physiol Nutr Metab 2016;41:S311-S327.

19) Korea Communications Commission. A survey on broadcast media usage behavior in 2019 [Internet]. Gwacheon: Korea Communications Commission;2020 [cited 2021 March 15]. Available from: https: $/ / \mathrm{kcc} . \mathrm{go} . \mathrm{kr} / \mathrm{user} . \mathrm{do}$ ? $\mathrm{mode}=$ view $\&$ page $=\mathrm{A} 02060100 \& \mathrm{dc}=601$ 00\&boardId $=1027 \& \mathrm{cp}=1 \&$ boardSeq $=48358$.

20) Australian Government Department of Health. Guidelines for healthy growth \& development for children \& young people (5 to 17 years): a guide for parents \& educators [Internet]. Canberra: Australian Government Department of Health;2014 [cited 2021 March 15]. Available from: https://www.health.gov.au/sites/de- fault/files/documents/2021/05/24-hour-movement-guidelines-children-and-young-people-5-to-17-years-brochure.pdf.

21) Tandon PS, Zhou C, Sallis JF, Cain KL, Frank LD, Saelens BE. Home environment relationships with children's physical activity, sedentary time, and screen time by socioeconomic status. Int J Behav Nutr Phys Act 2012;9:88.

22) Chen W, Adler JL. Assessment of screen exposure in young children, 1997 to 2014. JAMA Pediatr 2019;173:391-393.

23) Bucksch J, Sigmundova D, Hamrik Z, Troped PJ, Melkevik O, Ahluwalia N, et al. International trends in adolescent screen-time behaviors From 2002 to 2010. J Adolesc Health 2016;58:417-425.

24) Nigg CR, Wunsch K, Nigg C, Niessner C, Jekauc D, Schmidt SCE, et al. Are physical activity, screen time, and mental health related during childhood, preadolescence, and adolescence? 11-year results from the German Motorik-Modul longitudinal study. Am J Epidemiol 2021;190:220-229.

25) Kim Y. Analysis of mobile phone possession and use behavior of children and adolescents. KISDI STAT Report 2019;19:1-7 [Epub]. Available from: https://www.kisdi.re.kr/report/view.do?key=m210 $1113025790 \&$ arrMasterId $=4333447 \&$ masterId $=4333447 \&$ art $\mathrm{Id}=554166$.

26) Martin CA, Kelly TH, Rayens MK, Brogli B, Himelreich K, Brenzel A, et al. Sensation seeking and symptoms of disruptive disorder: association with nicotine, alcohol, and marijuana use in early and mid-adolescence. Psychol Rep 2004;94:1075-1082.

27) Wang $P$, Lei L, Wang $X$, Nie J, Chu $X$, Jin S. The exacerbating role of perceived social support and the "buffering" role of depression in the relation between sensation seeking and adolescent smartphone addiction. Pers Individ Differ 2018;130:129-134.

28) Jensen JD, Weaver AJ, Ivic R, Imboden K. Developing a brief sensation seeking scale for children: establishing concurrent validity with video game use and rule-breaking behavior. Media Psychol 2011;14:71-95.

29) Harden KP, Patterson MW, Briley DA, Engelhardt LE, Kretsch N, Mann FD, et al. Developmental changes in genetic and environmental influences on rule-breaking and aggression: age and pubertal development. J Child Psychol Psychiatry 2015;56:1370-1379.

30) Tansriratanawong $\mathbf{S}$, Louthrenoo $\mathbf{O}$, Chonchaiya $\mathbf{W}$, Charnsil C. Screen viewing time and externalising problems in pre-school children in Northern Thailand. J Child Adolesc Ment Health 2017;29: 245-252.

31) Yilmaz G, Demirli Caylan N, Karacan CD. An intervention to preschool children for reducing screen time: a randomized controlled trial. Child Care Health Dev 2015;41:443-449.

32) Sourander A, Helstelä L. Childhood predictors of externalizing and internalizing problems in adolescence. A prospective follow-up study from age 8 to 16. Eur Child Adolesc Psychiatry 2005;14:415423. 